\title{
Depth Profiling of Diffraction-based Security Features in Authentic and Counterfeit Banknotes
}

\author{
IOAN CRISTINEL NEGRU ${ }^{1}$, VIORICA VASILACHE ${ }^{2}$, ION SANDU2,3, ROMEO IULIAN OLARIU 4,5, PETRU OVIDIU TANASA ${ }^{1}$, \\ DANIEL POTOLINCA ${ }^{1}$, IRINA CRINA ANCA SANDU6* \\ ${ }^{1}$ Alexandru loan Cuza University of Iasi, Faculty of Geography and Geology, 20A, Carol I Blvd., Corp B-Etaj I, 700506, Iasi, Romania \\ ${ }^{2}$ Alexandru Ioan Cuza University of lasi, Interdisciplinary Research Department - Field Science, Arheoinvest Platform, 22 Carol \\ I Blvd., Corp G-Demisol, 700506, Iasi, Romania \\ ${ }^{3}$ Romanian Inventors Forum, 3 Sf. Petru Movila Str., BI. L11, Sc. A., III/3, 700089, Iasi, Romania \\ ${ }^{4}$ Alexandru Ioan Cuza University of lasi, Faculty of Chemistry, 11 Carol I Blvd., 700506, lasi, Romania \\ ${ }^{5}$ Alexandru Ioan Cuza University of Iasi, Integrated Center of Environmental Science Studies in the North-Eastern Region \\ (CERNESIM), 11 Carol I Blvd., 700506, Iasi, Romania \\ ${ }^{6}$ Munch Museum Munch Museet, Dept Conservat, N-530578 Oslo, Norway
}

\begin{abstract}
High printing quality of banknotes and the variety of security features implemented in banknotes make a big difference between the genuine notes and high-quality forgeries. The counterfeiter cannot reproduce or imitate the printing quality and all security features embedded in every banknote, such as Optically Variable Ink, Optically Variable Diffractive Images, or intaglio printing. The presentresearch focused on the examination of optically variable devices embedded on 50 Ebanknotes. The altered banknotes were examined using different techniques.
\end{abstract}

Keywords: banknotes, counterfeit, interference, optical variable devices, optical variable inks

At the present, to determine its authenticity of a banknote, authorities rely on visual inspection and fluorescence reaction. Not always visual examination proves that a banknote is genuine, therefore simple and non-destructive technique, such as the spectroscopic method (infrared and Raman), and microscopic examinations are very useful to assist in identification of a forgery. However, using these techniques, it is difficult to distinguish aged banknotes from high-quality forgeries that present similar spectroscopic features. Using mass spectrometry (MS) provides molecular information of chemical compounds in banknotes [1].

In this sense, for identification of chemical nature of component materials, structural and functional features, manufacturing technology, conservation status, up to the deep details of chemo-metric characteristics and traces of surface materials, complex methods are involved in the scientific examination of the banknotes in question [25]. An important role is held by the physical and chemical expertise of the banknotes with counterfeit elements or entirely falsified, which allows proof of guilt and identification of the counterfeiter, having a very important role in proving the guilt and whereabouts of the perpetrator [6-10].

The difference in quality between genuine and counterfeits banknotes depends on the level of security features embedded, and the equipment or competence of the counterfeiter. It is well known the so-called "superdollar plot". USD 100\$ banknotes were alleged to be very good imitation, then even for experts were difficult to notice the difference. The superdollarswere produced on an industrial scale, at the government level by North Korea [11].

As the quality of colour printers and resolution of scanners gradually developed, it forced authorities to add to banknotes additional security features that cannot be copied by colour copiers or desktop equipment, such as optically variable ink, metallic foils and diffractive optically variable image devices.

It is well known that it is easier for a counterfeiter to imitate banknotes that visually are good quality than it is harder to make a forged banknote with identical chemical composition of papers or inks.

For security standpoint, on banknotes frequently is used iridescent optically variable devices because colour copies cannot reproduce the optical effect, require advanced equipment and complex knowledge. Iridescent optically variable devices are based on light diffraction by gratings or light interference in thin film structures, and can be checked in first line by tilting, in order to result a positivenegative image, reverse in contrastor in colour conversions. These optical effects are well-defined and easy to recognize.

Using Optical Microscopy (OM), Scanning Electron Microscopy (SEM) coupled with X-ray Spectroscopy (EDX), and FTIR Spectroscopy, the paper analyses a series of banknotes to identify the main security features based on diffraction.

\section{Experimental part}

In the current study, various areas from genuine and forged notes were examined with different techniques employed that include: optical microscopy using a CARL ZEISS AXIO IMAGER Alm, with attached camera AXIOCAM, with magnification between 50x and 200x [12-14] used for visual examination of banknotes; scanning electron microscope - SEM VEGA II LSH, combined with an EDX detector type QUANTAX QX2 using 200.....1000x magnification, and with a 30kV acceleration tension and working pressure below $1 \times 10-2 \mathrm{~Pa}[15,16]$. Moreover, has been proposed a procedure with the use of another non-destructive technique: ATR-FTIR. FTIR spectra

* email: irina.sandu@munchmuseet.no 

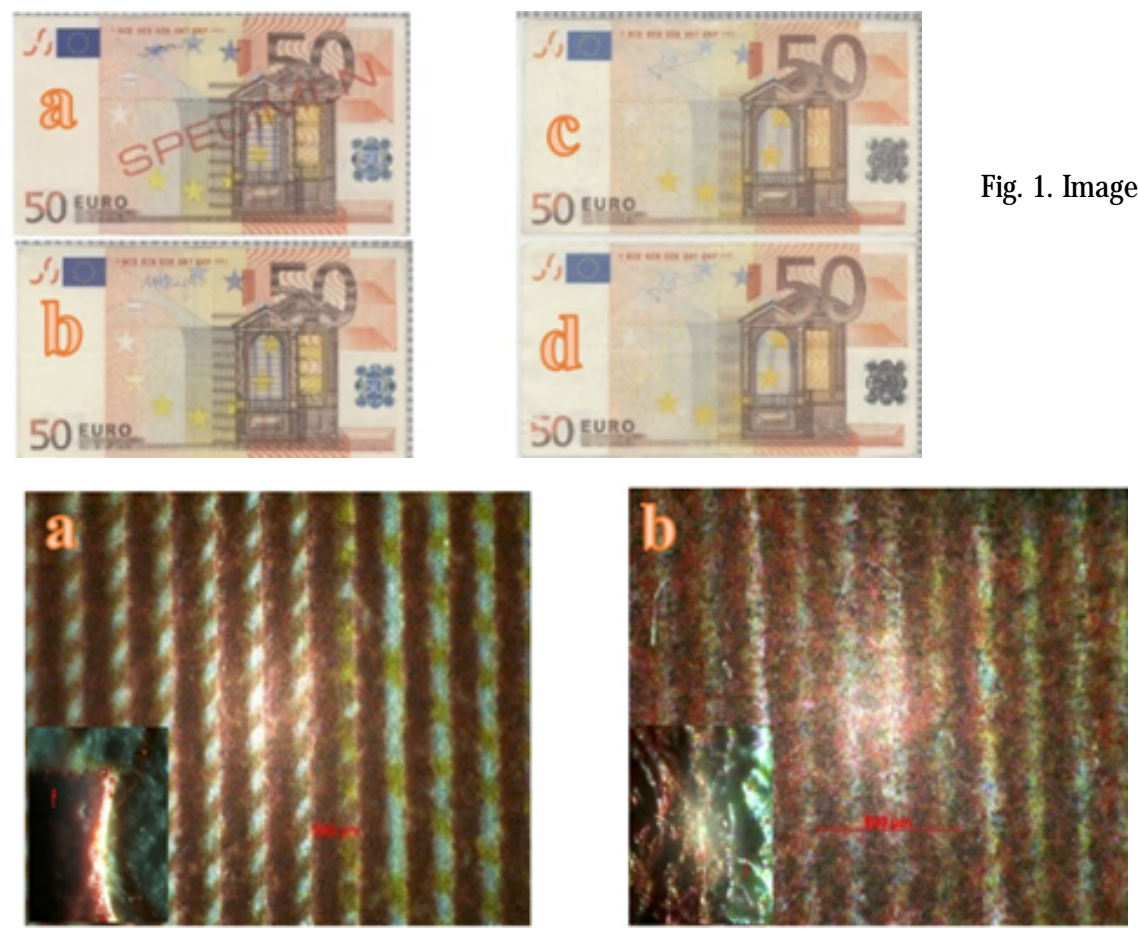

According to ATR-FIR examination, spectra obtain from

were obtained using a Vertex 70 FTIR equipped with accessories: ATR mode and RAMAN II. The spectra were recorded in the range of $4000-700 \mathrm{~cm}^{-1}$ [17-19].

There were compared four banknotes with $50 \in$ : one specimen (fig. 1 a), another genuine used banknote (fig. 1 b), along two counterfeit banknotes (fig. 1 c and d).

Three different areas from all 50 euro banknotes were selected for examination:

- on the recto (intaglio printing at the top of the banknote next to the nomination and optically variable image device at the bottom right, which is covered by a plastic film);

- on the verso (nomination of the banknote, printed with optically variable ink, on the bottom right side).

\section{Results and discussions}

The tactility of intaglio printing can be forged by line offset printing with tactile relief embossed that imitate very well the original printing, as these aspects are confirmed by OM examination (fig. 2a and b) and SEM (fig. 3a and b). The access to intaglio printing is limited to high security printing value documents, but embossing techniques are available on market.
Fig. 1. Images of genuine banknotes $(a, b)$ and counterfeit banknotes $(c, d)$
Fig. 2. OM imaging for: a - intaglio printing genuine; $b$ - imitated by embossing ink used for intaglio image, on both genuine banknotes (fig. 1a and b) appeared to be similar (fig. 4a and b), and very different position and intensity from forged ones (fig. $4 c$ and d). On forged notes its appear high peaks and different from genuine notes, on $1729.24 \mathrm{~cm}^{-1}, 1225.85$ $\mathrm{cm}^{-1}, 1018.65 \mathrm{~cm}^{-1}$ and $945.83 \mathrm{~cm}^{-1}$.

As security features, banknotes of $50 \in$ use diffractive optically variable image devices (OVD), along interference security image structure (optically variable ink). Optically variable ink (fig. 5a) consists of opaque micro flakes added to a transparent ink medium. During the printing, the tiny interference filter flakes must be orientation independent and symmetric about the aluminium mirror. During the printing process, the flakes align parallel to the substrate. The low refractive index of the $\mathrm{MgF}$ displays a large colour shift with angle of observation [20]. Counterfeiters can deceptive imitate security features as metallic foils or optically variable inks (fig. $5 b$ ).

As table 1 indicates for optically variable ink in forged banknote the amount of carbon it is four times more than in genuine notes. The carbonate peaks derive from calcium

Table 1

THE CHEMICAL COMPOSITION

\begin{tabular}{|l|c|c|c|c|c|c|c|c|c|c|}
\hline \multirow{2}{*}{ Samples } & \multicolumn{9}{|c|}{ The elemental composition (percentage by weight) \% } \\
\cline { 2 - 11 } & Carbon & Calcium & Magnesium & Titanium & Sulphur & Silicon & Aluminium & Oxygen & Chlorine & Barium \\
\hline $\begin{array}{l}\text { Intaglio ink } \\
\text { forged } \\
\text { banknote a }\end{array}$ & 24.77 & - & - & - & - & - & - & 75.23 & - & - \\
\hline $\begin{array}{l}\text { Intaglio ink } \\
\text { genuine } \\
\text { banknote c }\end{array}$ & 11.51 & 6.58 & 0.61 & 0.44 & 2.57 & - & 0.06 & 78.15 & - & - \\
\hline $\begin{array}{l}\text { OVD forged } \\
\text { banknote a }\end{array}$ & 13.91 & 3.55 & - & - & - & 2.17 & 1.88 & 57.79 & 15.21 & - \\
\hline $\begin{array}{l}\text { OVD } \\
\text { genuine } \\
\text { banknote c }\end{array}$ & - & - & - & - & 1.09 & 3.33 & 3.68 & 79.83 & 8.02 & 4.06 \\
\hline $\begin{array}{l}\text { OVI } \\
\text { forged } \\
\text { banknote a }\end{array}$ & 6.21 & 10.73 & - & - & - & - & - & 82.49 & 0.56 & - \\
\hline $\begin{array}{l}\text { OVI } \\
\text { genuine } \\
\text { banknote c }\end{array}$ & 27.81 & - & - & 1.17 & - & - & - & 71.02 & - & - \\
\hline
\end{tabular}



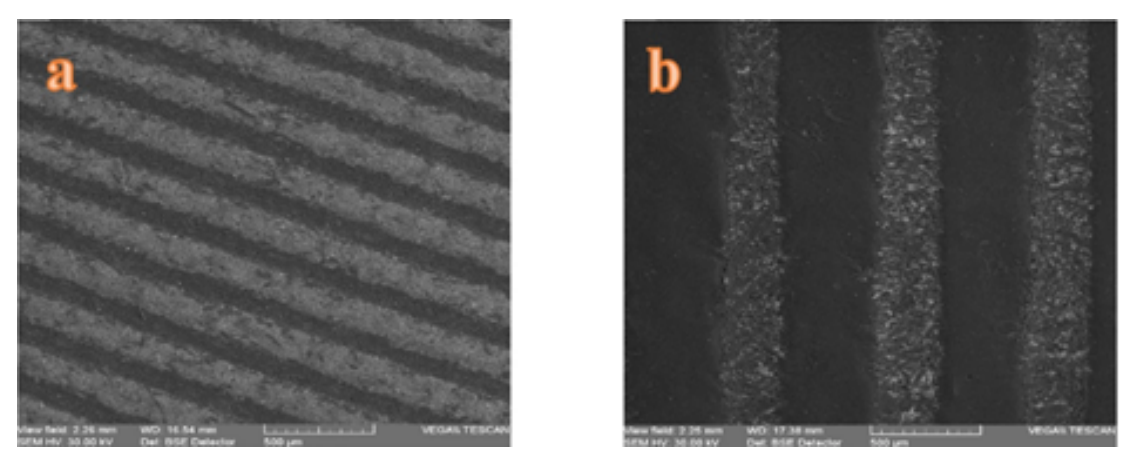

Fig. 3. SEM images for: a - intaglio printing genuine; $b$ - imitated by embossing

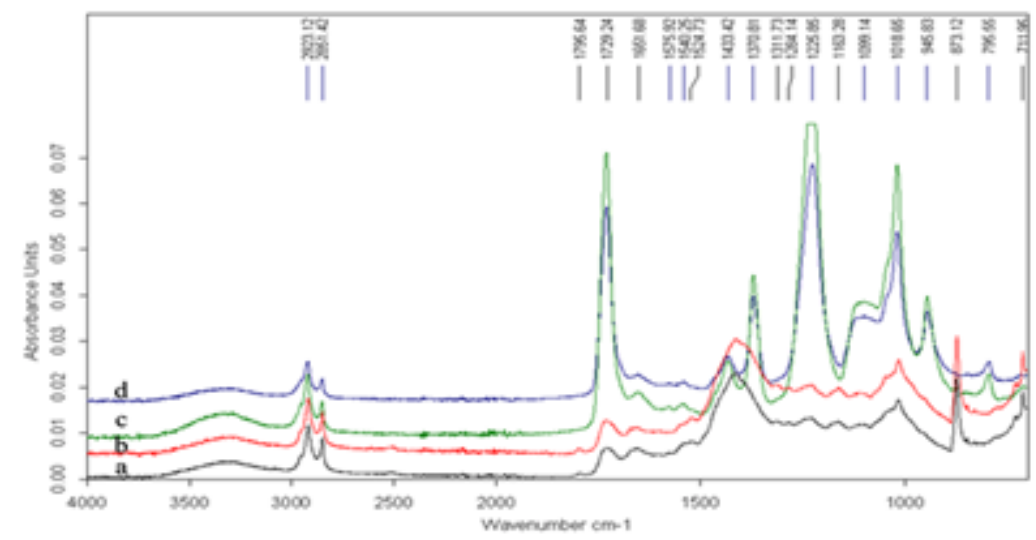

Fig. 4. Infrared spectra of the ink used for intaglio print from genuine $(a, b)$ and fake $(c, d)$ banknotes
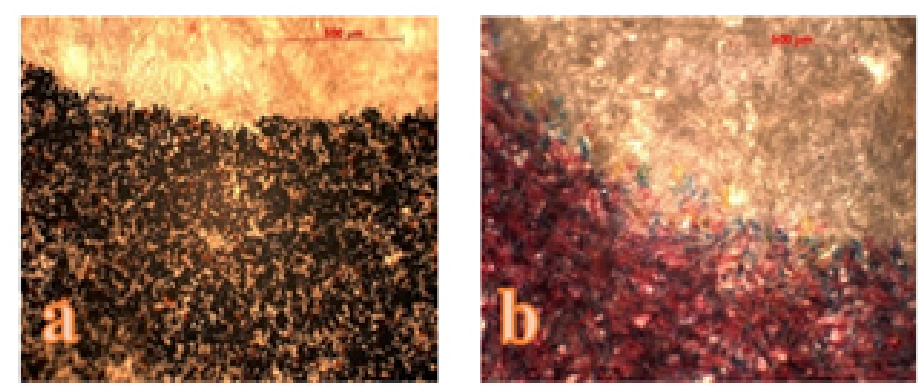

Fig. 5. OM imaging for: a - optically variable ink genuine; b - counterfeited by inkjet

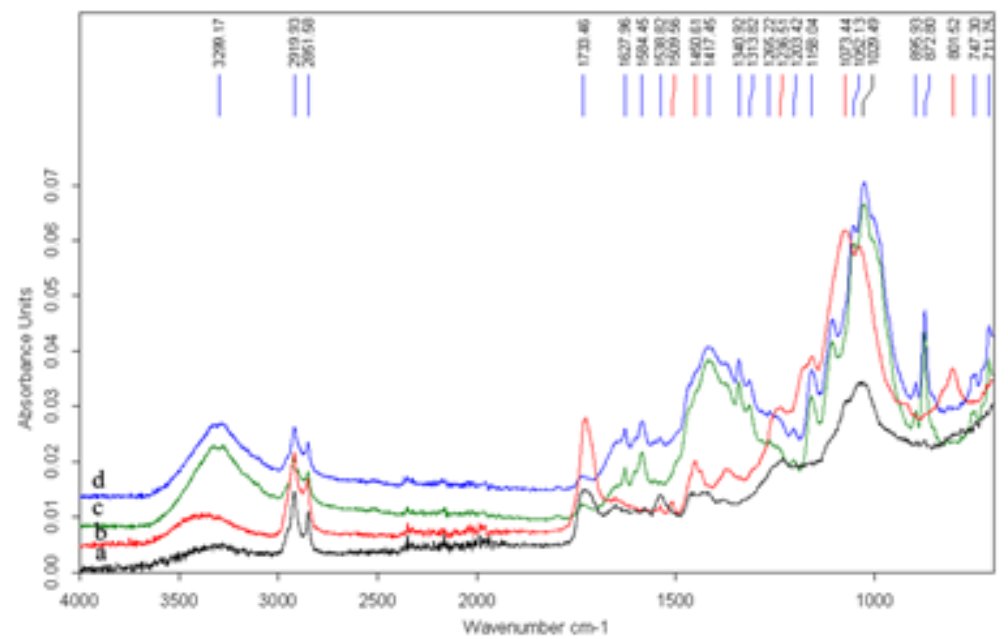

Fig. 6. Infrared spectra of the ink from interference security image $(\mathrm{OVI})$ structure from genuine $(\mathrm{a}, \mathrm{b})$ and fake $(c, d)$ banknotes

carbonate, used very fervently as a filer in the manufacture of paper.

The spectra indicate that the band at $1400 \mathrm{~cm}^{-1}$ is likely to result from carbonate peak with a big difference between genuine and forged banknotes (fig. 6). However, reproducibility of spectra collected on the corresponding location on genuine banknotes is quite high but there are slight differences. These singular aspects are for specimen banknote at $1073.44 \mathrm{~cm}^{-1}$ and $1236.22 \mathrm{~cm}^{-1}$ the intensity lower than the corresponding bands in the genuine use banknote.
According to the ATR technique, the spectrum corresponds to the plastic film which is covering metallic part of optically variable diffractive images (OVD), and the absorption bands identify as an acrylic polymer (fig. 7a and b) [21-26]. As figure 7 show, using SEM, it is a major difference in metallic structure surfaces from optically variable diffractive images of genuine (fig. 7a) and forged banknote (fig. 7b). Moreover, the optically variable diffractive images spectra from genuine banknotes (fig. $8 a$ and b) include peaks at $1725.11 \mathrm{~cm}^{-1}, 1434.86 \mathrm{~cm}^{-1}$, $1387.18 \mathrm{~cm}^{-1}, 1019.21 \mathrm{~cm}^{-1}, 913.50 \mathrm{~cm}^{-1} 750.59 \mathrm{~cm}^{-1}$ which does not correspond with those from forged banknotes. 

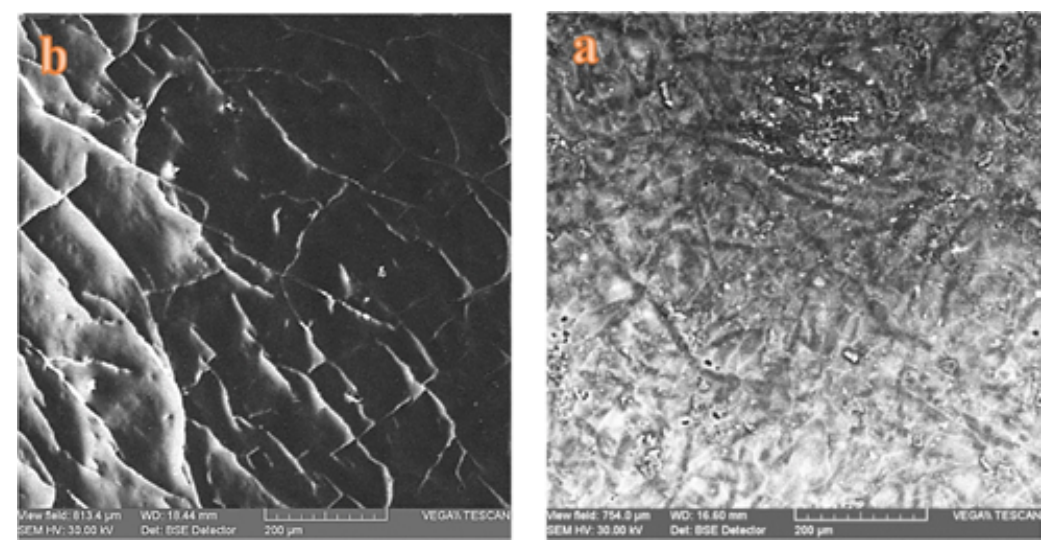

Fig. 7. SEM images of metallic structure surfaces from optically variable diffractive images (a) genuine and (b) counterfeit

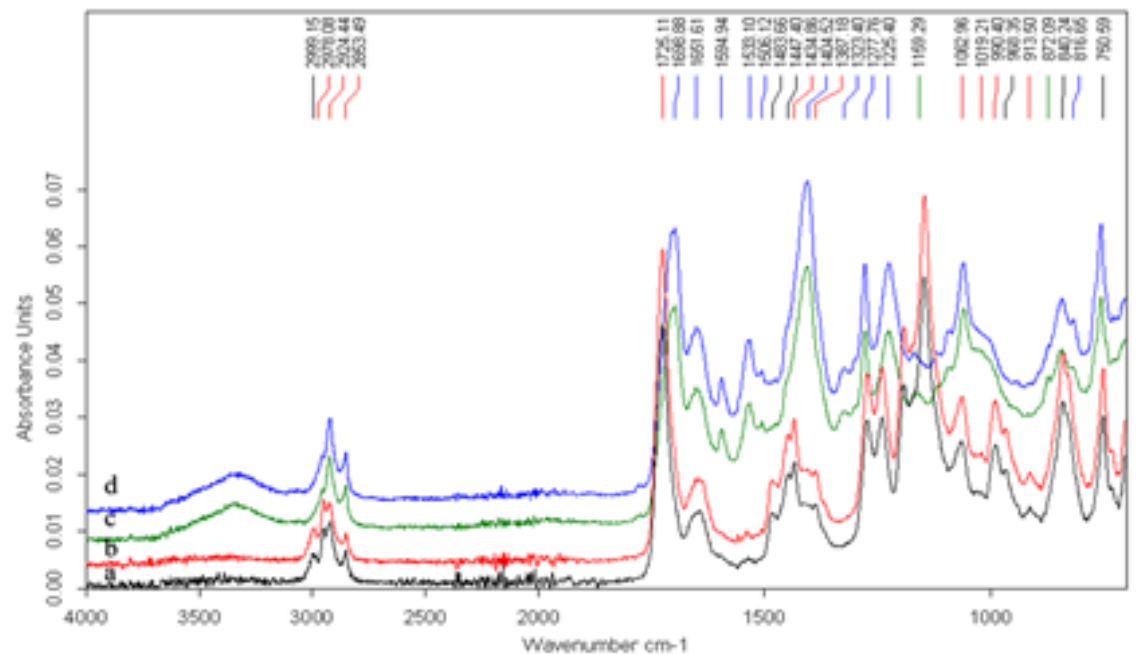

Fig. 8. Infrared spectra of metal area from optically variable diffractive images of genuine $(a, b)$ and fake $(c, d)$ banknotes

Spectral reproducibility between genuine notes is very high, as well as between forgeries.

\section{Conclusions}

This work has emphasised a methodology to identify a banknote using infrared spectroscopy combined with mass spectrometry. Spectroscopy signatures and mass spectrometry allow differentiating between genuine banknotes and forged ones,s after comparing the spectra measured for optically variable ink, optically variable image device and intaglio printing.

The examination of several areas of the banknotes, based on Optical Microscopy (OM) and FTIR Spectroscopy techniques is a fast procedure and non-destructive and allows us to recognize the differences between genuine and forged notes. Complementary, using Scanning Electron Microscopy (SEM) coupled with X-ray Spectroscopy (EDX), this discrimination can be extended with chemical information obtained from each area, even increasing number of security features examined, when itis necessary to distinguish any different falsification example.

Acknowledgement: CERNESIM Centre is gratefully acknowledged for the infrastructure used in this work.

\section{References}

1. SONNEX, E., ALMOND, M.J ., BAUM, J.V, BOND. J.W., Identification of Forged Bank of England $£ 20$ Banknotes using IR Spectroscopy, Spectrochimica Acta PartA: Molecular and Biomolecular Spectroscopy, 118, 2014, pp. 1158-1163.

2. POTOLINCA, D., NEGRU, I.C., VASILACHE, V., ARSENE, C., PADURARU, M., SANDU, I., Forensic Expertise of the Paper Support of Counterfeit Documents, Mat. Plast., 54, no. 1, 2017, p. 186
3. INEKE, J., SPRING, M. Scanning Electron Microscopy (SEM) and Energy Dispersive X-ray Spectroscopy (EDS or EDX), In: PINNA, D., GALEOTTI, M. \& MAZZEO, R. (eds.) Scientific Examination for the Investigation of Paintings. A Handbook for Conservator-restorers, Centro Di, Florenze, 2009, pp. 191-193.

4. SANDU, I.C.A., ROQUE, A.C.A., MATTEINI, P., SCHAFER, S., AGATI, G., CORREIA, C.R., VIANA, J.F.F.P., Fluorescence recognition of proteinaceous binders in works of art by a novel integrated system of investigation, Microscopy Research and Technique, 75, no. 3, 2012, pp. 316-324.

5. SANDU, I.C.A., BRACCI, S., SANDU, I., Instrumental analyses used in the authentification of old paintings - I. Comparison between two icons of XIXth century, Rev.Chim. (Bucharest), 57, no. 8, 2006, pp. 796-802.

6. BUDU, A.M., SANDU, I., VASILACHE, V., SIMIONESCU, A.E., SANDU, I.C.A., Effects of Human Skin Surface Lipids on Icons Painting Layer, Rev.Chim. (Bucharest), 66, no. 8, 2015, pp. 1212-1216.

7. SANDU, I., LUCA, C., SANDU, I.C.A., VASILACHE, V., Old paintings authentication through the identification of the polychrome layers materials - I. Gas-cromatography analyse, Rev.Chim. (Bucharest), 58, no. 10,2007 , pp. 879-886.

8. SANDU, I.C.A., VASILACHE, V., SANDU, I., LUCA, C., HAYASHI, M., Authentication of the Ancient Easel-paintings through Materials Identification from the Polychrome Layers III. Cross - section Analysis and Staining Test, Rev.Chim. (Bucharest), 59, no. 8, 2008, pp. 855-866. 9. SANDU, I.C.A., LUCA, C., SANDU, I., VASILACHE, V., HAYASHI, M., Authentication of the ancient easel paintings through materials identification from the polychrome layers - II. Analysis by means of the FT-IR spectrophotometry, Rev.Chim. (Bucharest), 59, no. 4, 2008, pp. 384 
10. SANDU, I.C.A., LUCA, C., SANDU, I., A study on the paintings cloth supports ageing degradation, Rev. Chim. (Bucharest), 50, no. 12, 1999 , p. 902

11. VAN RENESSE, R.L., Verifying versus Falsifying Banknotes, SPIE Vol. 3314, Conference on Optical Security and Counterfeit Deterrence Techniques II, San J ose, California, 28-30 J anuary 1998, pp. 71- 85. 12. DONNELLY, S., MARRERO, J.E., CORNELL, T., FOWLER, K., ALLISON, J, Analysis of Pigmented Inkjet Printer Inks and Printed Documents by Laser Desorption/Mass Spectrometry, Journal of Forensic Sciences, 55, no.1, 2010, pp. 129-135.

13. FUKUNANGA, K., OGAWA, Y., HAYASHI, S.I., HOSAKO, I., Tetrahert spectroscopy for art conservation, IEICE Electronics Express, 4, 2007, pp. 258-263.

14. VASILACHE, V., SANDU, I., MIRCEA, O., SANDU, A.V., Study on the Conservation State of a Gilded Silver Coin from XVI Century, Discovered in Romania, International J ournal of Conservation Science, 4, Special Issue, 2013, pp. 710-714.

15. KUCKOVA, S., SANDU, I.C.A., CRHOVA, M., HYNEK, R., FOGAS, I., MURALHA, V.S., SANDU, A.V., Complementary cross-section based protocol of investigation of polychrome samples of a 16th century Moravian Sculpture by optical, vibrational and mass spectrometric techniques, Microchemical J ournal, 110, 2013, pp. 538-544.

16.GENESTAR, C., PONS, C., Earth pigments in painting: characterisation and differentiation by means of FTIR spectroscopy and SEM-EDS microanalysis. Analytical and Bioanalytical Chemistry, 382, 2005, pp. 269-274.

17. MANSFIELD, J.R., ATTAS, M., MAJZELS, C., CLOUTIS, E., COLLINS, C., MANTSCH, H. H., Near infrared spectroscopy reflectance imaging: A new tool in art conservation, Vibrational Spectroscopy, 28, 2002, pp. 59-66.
18. MARUTOIU, C., BRATU, I., TRIFA, A., BOTIS, M., MARUTOIU, V.C., FTIR analysis of painting materials from the church Saint Paraschiva, of Poienile Izei, Maramures, Romania, International Journal of Conservation Science, 2, no. 1, 2011, pp. 29-35.

19. RUCAREAN, S.M., Conservation objects by paper support using nanomaterials, PhD. Thesis, Valahia University of Targoviste, IOSUD Engineering Science PhD School, 2014

20. VAN RENESSE, R.L., Optical Document Security, Artech House, London, 2005, pp. 234-235.

21. TAGHIZADEH, M.R., BLAIR, P., LAYET, B., BARTON, I.M., WADDIE, A.J., ROSS, N., Design and fabrication of diffractive optical elements, Microelectron. Eng., 34, 1997, pp. 219-242.

22. LEE, R.A., Micro-technology for anti-counterfeiting, Microelectron. Eng., 53, 2000, pp. 513-516.

23. LEECH, P.W., ZEIDLER, H., Microrelief structures for anticounterfeiting applications, Microelectron. Eng., 65, 2003, pp. 439446.

24. SCHIFT, H., HEYDERMAN, L.J ., AUF DER MAUR, M., GOBRECHT, J., Pattern formation in hot embossing of thin polymer films, Nanotechnology, 12, 2001, pp. 173-177.

25.NAKAMOTO, K., Infrared and Raman Spectra of Inorganic and Coordination Compounds, Parts A and B, John Wiley $\&$ Sons, New York, 1997.

26. COATES, J., Interpretation of Infrared Spectra, A Practical Approach, Encyclopedia of Analytical Chemistry (Editor R.A. Meyers), J ohn Wiley \& Sons Ltd, Chichester, 2000, pp. 10815-10837.

Manuscript received: 12.12 .2016 